\title{
Healthcare Financing in Nigeria: The Analysis of the Inequity Perspective
}

\author{
Akanni Olayinka Lawanson* \\ and \\ Sekinat Olaide Opeloyeru \\ Department of Economics \\ Faculty of Economics \\ University of Ibadan \\ Ibadan, Nigeria
}

\begin{abstract}
The volume and quality of healthcare needs vary from one individual to another but promoting access to the use of healthcare is germane to reduceleliminate inequity in healthcare. This paper examines the extent of equity in healthcare financing in Nigeria, and determine the relative progressivity of each source of healthcare financing in the country using waves 2 and 3 of the General Household Survey. Kakwani and Modified Kakwani (MDK) indexes were used to estimate progressivity of out of pocket payment (OOP) and social health insurance. Overall result indicates a vertical inequity favouring the non-poor (pro-rich), OOP as a source of financing was regressive and social health insurance was moderately progressive. Given that a more progressive healthcare financing approach tends to promote welfare and improve health status of the population, Nigeria will be better off promoting health insurance as a means of eliminating inequity in healthcare financing.
\end{abstract}

Key words: Equity, Out of Pocket, healthcare financing, poor and non-poor

\subsection{Introduction}

In recent years, healthcare system has been faced with diverse challenges due to the changes in societal factors such as ageing population, increasing expectations and demands of patients, progress in medical research, advancement in technology and scarcity of resources [1]. Given the increasing expectations and demands of patients, policy makers are being prompted to invest in healthcare programmes in order to cater for unmet healthcare needs, which may cause differences in socioeconomic status.

To promote the health of any population, the healthcare system of such country must focus on achieving the efficiency and equity objectives. However, Pursuit of efficiency in healthcare sector is usually based on the functioning of the market system, which allocates health resources to those that are able to pay because the market is out to maximize utility. The extent of readiness and amount the patient is willing to pay is considered to be an indication of the quantum of utility attached to health services. The implication is that the poor who cannot afford it are left out of the market pool, which is

\footnotetext{
${ }^{*}$ Corresponding author: Email: aolawanson@yahoo.com
} 
the origin of inequity (absence of equity). The need to achieve equal access to healthcare among the socioeconomic groups has led to the pursuit of equity as an important goal in the health sector. Most healthcare programmes today are geared towards narrowing the inequalities among socioeconomic groups so as to promote equal health.

The World Health Organisation (WHO) described equity in healthcare as the absence of avoidable differences among groups of people, whether those groups are defined socially, economically or geographically in accessing healthcare. At the heart of the debate, are two forms of inequity: social inequity due to poverty, ethnicity, and lack of education; while spatial inequity arises due to location of residence, such as rural, urban, hilly and forest areas that affect healthcare utilization [2]. Usually, social inequity is identified between two income groups, which are the poor, and the non-poor. Most poor people benefit less from the health systems than the non-poor and the cost of healthcare usually imposes huge burden on the poor households. According to [3], the poor suffer higher rates of mortality and morbidity than the non-poor.

Though, accessing healthcare services depend on the effectiveness of health system, however, irrespective of the effective provision of services, the issue of how healthcare is financed to guarantee equitable distribution of care cannot be neglected. Lagarde and Palmer [4] averred that payments for health services in form of out of pocket (OOP) and shortage of resources at the facility level is a major constraint to accessing basic health services by many of the world's poorest people. Consequently, the heavy financial burden of OOP on poor households may lead to disproportionate use of healthcare in different part of the world $[5,6]$.

The health financing system in Nigeria tends to be more market oriented due to large number of private healthcare facilities, with emphasizes on efficiency objective at the expense of equity objective. More so, the public healthcare facilities are characterized by existence of user charges, which put financial burden on the households. The number of hospitals in Nigeria was 3,534 in 2014, of which 2,584 were private hospitals and 950 were in the public sector [7]. Empirical studies on inequity have been analyzed basically according to income groups $[8,9,10,11,12,13,14]$. Inequity does not only exist as a result of income but could exit as a result of gender, age and residential location. Thus, in the light of this, equity objective appears to suffer a set back within the healthcare system of Nigeria. Regarding the burden of financing healthcare, OOP dominates the healthcare financing landscape in Nigeria, as over 70 percent of healthcare expenditure in Nigeria is from OOP $[15,16]$. Apart from the fact that OOP restricts access to healthcare, low utilization of basic healthcare services also account for high morbidity and mortality among the socioeconomic groups. Hence, understanding the dimension of healthcare equity in Nigeria is crucial. Thus this paper examines the extent of equity in healthcare financing in Nigeria, and determine the relative progressivity of each source of healthcare financing in the country. The paper also examined the extent of equity along the rural-urban dimension.

\subsection{Background on Healthcare, Poverty and Income Inequality in Nigeria}

Both public and private sectors are involved in the operations of the Nigerian health system. The public involvement cut across the three tiers of governments: federal, states and local governments, with differing roles and responsibilities. In principle, the federal level, under the auspices of Federal Ministry of Health in collaboration with National Health council is responsible for the formulation of health policy for the country, as well as direct provision of healthcare services through the tertiary and teaching hospitals and national laboratories. In addition, the federal ministry of health intervenes in instances of health crisis and emergencies, by collaborating with state and local government in rectifying health challenges of the nation. The responsibilities of the State Ministries of Health $(\mathrm{SMOH})$ center more on the secondary health institutions, such as hospitals, clinics, and related facilities. They are also involved in providing technical, monitoring and supervisory role for the local government in the management of primary healthcare facilities. At the local government level, the Local Government Areas (LGAs) are responsible for the provision of primary healthcare. This level is the least funded and therefore has not been able to properly provide and organize primary healthcare, creating a very weak base for the healthcare system [17]. 
In Nigeria, healthcare is financed through the combination of general revenue, OOP, health insurance and external funding. Out of the four financing mechanisms, OOP is the most dominant way of channelling funds to healthcare providers. OOP dominates the payment landscape, with more than two-third of the total health expenditure from household as far back from the colonial days while the allocation of government at different levels is less than one-quarter of the total health expenditure. This necessitated the establishment of the Nation Health Insurance Scheme (NHIS) in 1999 to lighten the financial burden on households. Since the commencement of NHIS in 2005 less than 8 percent of the formal sector is covered, while application to the informal sector is still limited to a few piloted schemes in a number of states.

The performance of the Nigeria health system in terms of management and financing is relatively poor. The latest world life expectancy at birth ranking by World Health organization (WHO) ranked Nigeria 178 among 201 countries. The life expectancy at birth of 51.3 years in 2011, only slightly improved to 53.8 years in 2017. The life expectancy however differs between male and female, with the formal being consistently higher and growing faster. While the life expectancy for male of 50.6years for male in 2011, improved by around 2 years to 52.8 years in 2017, the life expectancy for female of 52 years in 2011, increased by 3 years to 55 years in 2017.

Though mortality rates in Nigeria is relatively high, the country's health sector has made some appreciable progress in achieving continuous decline in mortalities. Statistics from series of NDHS for 2003, 2008, and 2013, clearly shows declining mortality rates across different categories. Both neonatal and post-neonatal mortalities progressively declined from 48 and 52 per 1,000 live births, respectively in 2003 to 37 and 31 per live births, respectively in 2013. Similar trend was also observed in respect of infant, child, and under-five mortality rates which declined from 100, 112, and 201 per 1,000 live births, respectively in 2003 to 69, 64, and 128 per 1,000 live births, respectively in 2013 . Despite the further drop in infant mortality in Nigeria to 64.8 per 1,000 live births in 2017, the country is ranked by WHO as having the third highest rate in the world. The 2015 estimates for maternal mortality rate for Nigeria was put at 814 per 100,000 live births.

Both communicable and non-communicable diseases constitute major causes of morbidity and mortality in Nigeria. WHO ranks the country first in death caused by tuberculosis in the world at 190.61 per 100,000 population deaths, second in death caused by influenza and pneumonia at the rate of 228.17 per 100,000 population deaths, and fourth in death caused by diarrhea at the rate of 127.79 per 100,000 population deaths. Prevalence of malaria parasite is still high in Nigeria, with an average prevalence of 42 percent among children under age 5 and zonal variations ranging from 28 percent in the South East to 50 percent in the South West [18]. Malaria accounted for more than 18 percent of the total deaths in the country in 2017. Though malaria can be prevented at low cost, it remains the major cause of death among children and mothers in Nigeria, [18], accounting for about 11 percent of under-five deaths in 2017. According to USAID report on global health, Nigeria has the second largest number of people living with HIV/AIDS globally and accounts for 9 percent of the World HIV/AIDS burden [19]. In 2016, HIV/AIDS was reported to account for more than 7 percent of the total death in Nigeria.

High incidence of poverty and income inequality exists in Nigeria. Despite the abundance of natural resources in the country, the incidence of poverty has been on the increase over the years. In 2003/2004, about 80 million Nigerians lived below the poverty line in absolute term, representing 64.2 percent poverty incidence. The poverty incidence worsens in 2009/2010, increasing to 102.2 million, representing 62.6 percent poverty incidence in Nigeria. The incidence of poverty differs significantly between the rural and urban areas of the country. While rural poverty was estimated at 73.4 percent and 69.0 percent for years 2003/2004 and 2009/2010, respectively, the estimates for the urban area are lower at 52.2 percent and 51.2 percent in 2003/2004 and 2009/2010, respectively. The faster decline in the rural poverty than the urban poverty between 2003/2004 and 2009/2010, may be attributed to rural-urban migration. Recent statistics and reports refer to Nigeria as the new headquarters of poverty in the World; having the largest number of poor people ahead of India [20] Compounding the poverty issue in Nigeria is the increasing widening of income inequality in the country. While the top 20 percent of the population account for almost half (45\%) of the National Income, the bottom 20 percent of the population shares only 6 percent of National Income in 1986. This actually worsens in 1996, with more than half (52.11\%) of the National Income cornered by the 
top 20 percent of the Nigerian population. More recent estimates from NBS show that the top 30 percent (richest) of the population slightly dropped from accounting for accounting for 59.42 percent national income in 2013 to 58.39 percent in 2016, while the share of the bottom 30 percent (poorest) more or less remained the same at around 11.4 percent over the period 2013 to 2016.

\section{0 Review of Related Literature}

Equity has been considered and accorded deferring meaning by many authors, thus a consensus definition of the term is far between. Some treated it in relation to healthcare or health, which encompasses access; financing and utilization, while some approach it in relation to healthcare delivery and policies. Equity suggests existence of net benefit transfers from higher income groups to lower income groups [21]. Existence of equity helps to distribute goods and services in a manner that ensure fairness among social class or race. Equity in healthcare tends to receive greater attention in the recent time due to the shift in the demand side factors: the cost of healthcare, real family income and attitudes toward the use of health services. These factors have led to an outstanding debate on equity in financing, equity in accessing, equity in utilization of healthcare and how each should be measured.

One of the central arguments in healthcare financing is the question of who is responsible for payment incurred in obtaining healthcare. The focus in the literature as regards equity in healthcare financing is on the issue of how far healthcare is financed according to ability to pay. Irrespective of the issue addressed regarding equity in healthcare, there are two dimensions to equity- vertical and horizontal. The definitions of horizontal and vertical equity clearly rest on value judgment and on positive assessments of the relationships between variables and about their effects on health [22]. Vertical equity in healthcare financing is the extent to which individuals or groups of dissimilar ability to pay making unequal payments for healthcare $[8,23]$. Horizontal is the extent to which individuals or groups of equal ability to pay end up making equivalent payments for healthcare, regardless of their age, gender, place of residence, trade union membership, marital status and any other personal characteristics that is non-health related [8]. However, Sen [24] avers that equality scenario does not mean equality to enjoy healthcare, but rather those with equal needs should be treated equally (horizontal) and those with unequal need should be treated unequally (Vertical).

Analyzing equity issues in healthcare financing, Neil [25] proposes a theoretical approach of redistributive taxation method that is based on equal benefits paradigm and not equal sacrifice principle for equity in financing to be achieved. Considering health as a public good, the approach is structured along the use of taxes to finance public goods to equally benefit each agent. Equal benefit paradigm explains how taxes and expenditures should be structured to ensure benefit to each agent is the same. Most empirical works on equity focus on vertical equity (progressivity), horizontal and reranking or redistribution effect of financing healthcare.

Kakwani [26] and Renynolds and Smolensky [27] provided two summarized progressivity indexes: Kakwani progressivity index (KPI) and Renynolds-Smolensky (RS) commonly used to study equity in healthcare financing in the literature. KPI summarizes the entire range of income distribution over the population and assesses aggregate deviation of a payment schedule from proportionality. It is the difference between the area of the Lorenz curve (Gini Coefficient) and the concentration curve of healthcare payment (concentration index). [28] provided a little modification to the KPI referred to as Modified Kakwani (MDK) with an advantage that the index could be interpreted as the income or total expenditure elasticity for healthcare expenditures. MDK is the ratio of the concentration index to the Gini index of income instead of the difference used by Kakwani [26]. It is based upon life cycle utility or permanent income hypothesis, which enables the index to be interpreted as income or total expenditure elasticity. Similarly, RS captures the magnitude of the deviation of healthcare payment through pre-payment index and post payment of healthcare index. Both measures focus on vertical equity and are associated with ability to pay for healthcare. Other measures of equity in healthcare financing focus on either horizontal equity or re-ranking effect of income, such as: $[29,30,31,32,33$, $34,35,36]$.

Empirical studies on equity in healthcare financing are very few in Africa. Majority of the related works are on developed countries. The few ones on Nigeria cover limited geo-political zone $[37,15$, 
38], while [10] covers the entire country. These studies revealed that different financing sources can either be regressive, progressive or proportional. The outcome of results generally depends on methodology, statistical grouping of population according to income (quintiles, Deciles and percentiles), composition of expenditure, composition of out of pocket payment, and the type of financing system adopted in different countries.

[23] found the taxation method, private health insurance and social insurance to be regressive in the Dutch healthcare system. In addition, [39] also found the contributions of community health insurance to be regressive as well. Contrarily, [13] results were inconclusive on these methods, as they found no potential progressive feature of any of the available insurance schemes with the use of the aggregate approach. However, the disaggregated approach reveals a progressive aspect, for over half of the population, of the government health insurance scheme. Others studies like $[39,40]$ found insurance schemes to be strongly progressive while studies by $[41,42]$ found insurance schemes of healthcare to be mildly or slightly progressive.

The common method of financing in developing countries is the out of payments (OOPs) method of financing healthcare. In the context of OOP, majority of the studies found evidence of regressivity, with the burden of OOPs expenditures being unequally distributed among income groups $[13,8,39$, $40,41,10,38,43]$ while few authors like [42, 15] found OOPs to be mildly or moderately progressive.

\subsection{Theoretical Framework and Model Specification}

This study adopts the framework of equal benefits paradigm by [25]. The study assumes that healthcare is a social good, provided by both the private and public sectors.

Healthcare as a social good is not free; payment is necessary, which is paid directly (price mechanism) or indirectly (health insurance). The model considers a set of $\mathrm{n}$ agents with the following Von -Neuman-Morgenstern cardinal utility function:

$$
U=u(y, x)
$$

where the agent's real income is represented by $y$, and $x$ is the quantity of healthcare. The principle of equal sacrifice holds that payment for healthcare should impose the same burden or sacrifice on each agent, where this burden is defined as the agent's utility when he/she needs healthcare and pay, minus his utility when he/she needs healthcare, but not ready to pay.

$$
u\left(y_{i}-p_{i}, x\right)-u\left(y_{i}, x\right)=u\left(y_{j}-p_{j}, x\right)-u\left(y_{j}, x\right) \quad \forall \mathrm{i}, \neq \mathrm{j}
$$

By not paying for healthcare, the agent's utility reduces to $u\left(y_{i}, 0\right)$, thus change in benefits in equation 4.2 becomes:

$u\left(y_{i}-p_{i}, x\right)-u\left(y_{i}, 0\right)=u\left(y_{j}-p_{j}, x\right)-u\left(y_{j}, 0\right) \quad \forall \mathrm{i}, \neq \mathrm{j}$

Incorporating the benefits from government expenditures on healthcare and superimposing the Paretian principle on equation 4.3 transform the principle of equal sacrifice to equal benefit paradigm. By implication, with a diminishing marginal utility of income, an agent payment for healthcare must increase as his income increases. In addition, payments for healthcare must be progressive if the elasticity of the marginal utility of income is greater than one in absolute value, regressive if the elasticity is less than one, and proportional to income when it is unity.

\subsection{Methodology}

Both Kakwani Progressivity index (KPI) and Modified Kakwani progressivity index (MDK) were computed to generate the degree of variation in healthcare payment proportionality that is based on vertical equity. Relating to healthcare payments elasticity, application of Kakwani [26] to healthcare revolves around payments progressivity. Given an individual income $y$ as a random variable with a mean $\mu$ and probability distribution function $f(y)$, the proportion of the income of units having income less than or equal to $y$, can be represented by $f_{1}(y)$. The relationship between $f(y)$ and $f_{1}(y)$ is called Lorenz curve of income $y\left[L_{y}(p)\right]$. Denoting healthcare payments made by the 
units having income less than or equal to $y$ by $f_{1}[(T(y))]$, the concentration curve of healthcare payment $\left[L_{T}(p)\right]$ defines the relationship between $f(y)$ and $f_{1}[(T(y))]$.

The $\operatorname{KPI}(K)$ is represented by the difference between the pre-financing Gini coefficient $\left(\mathrm{GINI}_{\mathrm{pre}}\right)$ and the concentration Index of medical payment (CI).

$K=C I-G I N I_{\text {pre }}$

$\mathrm{CI}$ indicates how health financing is related to income. A positive (negative) value indicates that the non-poor (poor) bear a greater share of financing than the poor (non-poor). The geometric form of KPI $\left(\mathrm{K}_{\mathrm{p}}\right)$ can be expressed as the area under the curve, which is of the form:

$$
K_{p}=2 \int_{0}^{1}\left[L_{y}(p)-L_{T}(p)\right] d p
$$

Where $\mathrm{p}$ indicates household ranked in gross income. The first part on the right-hand side of the equation represents the Lorenz curve while the second part is the concentration curve of medical payment ranked in ascending order of cumulative share of the population. The value of KPI ranges between -2 and 1. A negative (positive) Kakwani Index indicates a regressive (progressive) financing mechanism, while value zero is indicative of proportional financing. Also, if the payment concentration curve lies above the Lorenz curve, one can conclude that the lower income brackets contribute a greater proportion of total healthcare financing than the proportion of income they receive and that the system is therefore inequitable. If the concentration curve lies below (above) the Lorenz curve, it indicates an inequitable system. If the concentration curve lies on the Lorenz curve, it indicates direct proportionality. It is also possible for the payment curve to cross the Lorenz curve. This suggests that the financing system is mixed i.e. is regressive for some income groups and progressive for others. If the payment curve crosses the Lorenz curve, the outcome depends on which of the negative or positive value outweighs the other, as such, the overall index is ambiguous.

The modified KPI (MDK) proposed by [28] is the ratio of the concentration index to that of Gini coefficient:

$$
\mathrm{MDK}=\frac{C I}{\text { Gini }_{\text {pre }}}
$$

Decomposing the above equation into various expenditure components is similar to the decomposition of the concentration index for medical payments. Let A and B represent expenditure component of OOP and Social insurance contributions, respectively, such that the expenditure shares of the medical payments in the total expenditure is written as:

$$
w_{f}=\frac{\mu_{f}}{\mu}, f=A, B
$$

Where $\mu_{f}$ is the average expenditure for component of the whole population and $\mu$ is the average total expenditure for medical payments. While the concentration index is decomposed into:

$$
C I=w_{A} C I_{A}+w_{B} C I_{B}
$$

the modified Kakwani measure is decomposed as follows

$$
\begin{aligned}
& M D K=w_{A} K_{A}+w_{B} K_{B} \\
& M D K=w_{A} \frac{C I_{A}}{\text { Gini }_{\text {pre }}}+w_{B} \frac{C I_{B}}{\text { Gini }}
\end{aligned}
$$

The relationship between the line of equality, Lorenz curves and healthcare payment concentration curves can be geometrically presented. The Lorenz curve plots the cumulative percentage of consumption against the cumulative share of population ranked by quintiles. The gap between the equality line and the Lorenz curve represents household income inequality: the closer the curve to the equality line, the lower is the inequality magnitude. Concentration curves plot the cumulative share of 
health payments against the cumulative share of the population, ranked from the first 20 percent to the last 20 percent of consumption while the difference between the Lorenz curve and the concentration curves explains the progressivity in healthcare financing. Overall, the combination of the Lorenz and payments concentration curves is a representation of the effect of healthcare financing on the distribution of household living standards. Indeed, when the health payment concentration curve lies below the Lorenz curve, it implies progressivity. That is, the distribution of health payment is more unequal than the distribution of income. Similarly, when the health payment concentration curve lies above the Lorenz curve, it implies that the financing system is regressive and by implication, the distribution of health payment is more equal than the distribution of income. Proportional health financing in this graphical analysis, implies that both Lorenz curve and concentration curve coincide, which implies that the distribution of income and health

\subsection{Data}

This paper extracted data from the second (wave 2) and third round (wave 3) of General Household Survey (GHS) conducted jointly by the Nigerian National Bureau of Statistics (NBS), the Federal Ministry of Agriculture and Rural Development (FMA \& RD) and the World Bank as part of the Integrated Surveys on Agriculture (ISA) program in 2012/2013 and 2015/2016 respectively. The two data sets were generated from the 36 states and FCT in Nigeria using multistage sample technique. The GHS sampled 5,000 households out of 22,000 households selected from 60 primary sampling units (PSU).The data sets give the snapshot of health seeking behavior of individuals for post introduction of the National Health Insurance Scheme (NHIS) in Nigeria, and data from 2009 National Health Accounts (NHA) to place weight on available sources of financing healthcare in Nigeria. Data extracted from waves 2 and 3 are the size of each household, age of the respondents as at the completion of the questionnaire, residence (sector) of the respondents, geopolitical zone, total household food and non- food consumption, total amount paid to healthcare providers per household (including cost of drugs and medical supplies) and total amount contributed to social insurance pool.

\section{0 Results and Discussion}

\subsection{Descriptive statistics}

The summary statistics of the 2012/13 and 2015/16 data sets used for the analysis in this paper are presented in Tables 1. An average national household size for the two waves ranges between 6.4 and 6.8 , with rural and urban households size of approximately 2 to 5 persons respectively. The average age of 52 years of respondents in the survey did not significantly differ in the two data sets. The average mean for social insurance contribution shows that households contribute less than $\$ 1000$ to the insurance pool per year while the average mean of out of pocket payment is at least $\$ 2000$ for both periods under consideration. Surprisingly, per capita expenditure for household double in $2015 / 2016$ compared to 2012/2013. For instance the national nominal expenditure of the household increased from the mean per capita expenditure of $40,157.5$ for the period of 2012/2013 to $\$ 83,551.1$ for the period of 2015/2016, representing more than 100 percent increase.

Table 1: Descriptive statistics for 2012/2013 and 2013/2016 GHS

\begin{tabular}{|c|c|c|}
\hline & GHS 2012/2013 & GHS 2015/2016 \\
& Mean & Mean \\
\hline
\end{tabular}




\begin{tabular}{|l|c|c|}
\hline Household size (National) & 6.4 & 6.8 \\
\hline Household size (Rural) & 4.6 & 4.9 \\
\hline Household size (Urban) & 1.8 & 2.0 \\
\hline Per -capita expenditure (National) & $40,157.5$ & $83,551.1$ \\
\hline Per -capita expenditure (Rural) & 23,753 & $65,145.6$ \\
\hline Per -capita expenditure (Urban) & $66,580.5$ & $122,607.8$ \\
\hline $\begin{array}{l}\text { Social insurance contribution } \\
\text { National) }\end{array}$ & 381 & 519.6 \\
\hline Social insurance contribution (Rural) & 105.1 & 363.8 \\
\hline Social insurance contribution (Urban) & 275.9 & 362.8 \\
\hline Out of pocket (National) & $7,150.5$ & $8,109.6$ \\
\hline Out of pocket (Rural) & 4510.2 & $8,109.6$ \\
\hline Out of pocket (Urban) & $2,510.2$ & $3,086.8$ \\
\hline Age of respondent (National) & 52 & 52.8 \\
\hline Age of respondent (Rural) & 52.1 & 52.8 \\
\hline Age of respondent (Urban) & 52.1 & \\
\hline
\end{tabular}

\subsection{Progressivity Indexes for 2012/2013 and 2015/2016}

The Gini coefficients relating to the pre-financing inequality index for 2012/2013 and 2015/2016 are reported in Tables 2 and 3, respectively. Overall, there are evidences of existence of the income inequality in Nigeria, however, the pace of inequality appears to have slightly subsided from the value of Gini coefficient is approximately 0.428 in $2012 / 2013$ to 0.439 , signifying income inequality exists in Nigeria, though not a perfect inequality. The Gini coefficients for urban and rural areas are approximately 0.572 and 0.566 , respectively. Concentration indexes for OOP, social insurance contributions and total payment are positive, implying that the rich quintiles bear a greater share of financing than the poor quintiles (pro- poor). The results shows that the health insurance financing if progressive in Nigeria. The positive KPI result for 2012/2013 for social insurance financing is a reflection of the proportional nature of contribution to income of the health insurance scheme in the country. However, while the results for 2015/2016 show progressivity in total estimate and for urban, there are indications to the existence of progressivity in health insurance financing in the rural area, as the KPI is negative. This result is explained by the community health insurance mode characterizing the rural area, in which contributors pays a lump sum amount as insurance premium. Participants' contribution does not reflect the ability to pay, because in the informal sectors (as the case in the rural area), determination of income of participants is always a challenge. Thus there is bound to be proportionality discrepancies in healthcare financing among community health insurance participants. 
On the general, with exception of the KPI results for rural in 2015/2016, healthcare financing through social insurance contribution is concentrated among the rich far more than their income.

Table 2: Progressivity Indexes (2012/2013)

\begin{tabular}{|c|c|c|c|}
\hline & Total & Urban & Rural \\
\hline Gini Coefficient & 0.4282 & 0.5725 & 0.5657 \\
\hline Concentration Index (Social insurance contributions) & 0.5756 & 0.7798 & 0.8373 \\
\hline Concentration Index (OOP payment) & 0.2151 & 0.2599 & 0.3619 \\
\hline Concentration Index (Total payment) & 0.2209 & 0.3091 & 0.3727 \\
\hline $\begin{array}{l}\text { Kakwani Progressivity Index (KPI- Social insurance } \\
\text { contributions) }\end{array}$ & 0.1474 & 0.2073 & 0.2717 \\
\hline Kakwani Progressivity Index (KPI- OOP payment) & -0.2131 & -0.3126 & -0.2038 \\
\hline Kakwani Progressivity Index (KPI- Total payment) & -0.2074 & -0.2634 & -0.1930 \\
\hline $\begin{array}{l}\text { Modified Kakwani Index (MDK- Social insurance } \\
\text { contributions) }\end{array}$ & 1.3442 & 1.3620 & 1.4801 \\
\hline Modified Kakwani Index (MDK- OOP payment) & 0.5023 & 0.4539 & 0.6397 \\
\hline Modified Kakwani Index (MDK- Total payment) & 0.5159 & 0.5399 & 0.6397 \\
\hline
\end{tabular}

On the other hand, there are indications that OOP of financing healthcare is regressive. The KPI results for both 2012/2013 and 2015/2016 are negative for total, rural and urban, indicating that OOP payment is concentrated among the poor than concentration of their income. Overall, KPI for total payment for healthcare is negative and it is moderately regressive as it is less than 0.5 all through. This is a reflection of the relative dominance of OOP as method of financing healthcare compared to health insurance, meaning the burden of financing healthcare rest more on the poor than the non-poor. The MDK estimates, further confirm the existence regressive healthcare financing for health insurance, progressive for OOP and the total healthcare financing. The MDK estimates for health insurance are greater than one, while the estimates for the OOP and total health expenditure are less than one. By interpretation, the above one values of MDK estimates for health insurance shows that the ratio of healthcare expenditure to income reduces with income, whereas the below one values of MDK estimates for OOP and total health expenditure reveals that the ratio of healthcare expenditure to income increases with income.

Table 3: Progressivity Indexes (2015/2016)

\begin{tabular}{lccc} 
& Total & Urban & Rural \\
\hline Gini Coefficient & $\mathbf{0 . 4 3 8 9}$ & $\mathbf{0 . 3 8 9 2}$ & $\mathbf{0 . 4 2 3 8}$ \\
Concentration Index (Social insurance contributions) & $\mathbf{0 . 7 6 4 7}$ & $\mathbf{0 . 6 7 1 8}$ & $\mathbf{0 . 0 0 0 0}$ \\
Concentration Index (OOP payment) & $\mathbf{0 . 3 9 4 7}$ & $\mathbf{0 . 3 2 4 3}$ & $\mathbf{0 . 4 1 3 9}$ \\
\hline
\end{tabular}




\begin{tabular}{|c|c|c|c|}
\hline Concentration Index (Total payment) & 0.4006 & 0.3609 & 0.4139 \\
\hline $\begin{array}{l}\text { Kakwani Progressivity Index (KPI- Social insurance } \\
\text { contributions) }\end{array}$ & 0.3257 & 0.2826 & -0.4238 \\
\hline Kakwani Progressivity Index (KPI- OOP payment) & -0.0442 & -0.0649 & -0.0098 \\
\hline Kakwani Progressivity Index (KPI- Total payment) & -0.0383 & -0.0284 & -0.0098 \\
\hline Modified Kakwani Index (MDK- Social insurance contributions) & 1.7423 & 1.7261 & 0.0000 \\
\hline Modified Kakwani Index (MDK- OOP payment) & 0.8992 & 0.833 & 0.9766 \\
\hline Modified Kakwani Index (MDK- Total payment) & 0.9127 & 0.9273 & 0.9766 \\
\hline
\end{tabular}

The MDK index for OOP and total healthcare payment is less than one. This implies that ratio of healthcare expenditure to income decreases with income. When the KPI is negative the MDK is positive but less than one, when the KPI is positive, the MDK is positive and greater than one. Therefore, both KPI and MDK are suggesting the same direction for this analysis. From the welfare perspective, as long as the MDK is positive and greater than one, it implies that relatively poor households have limited access to healthcare.

\subsection{Lorenz curves and Payment Concentration Curves}

Figure 1A reveals that the Lorenz curve is below the equality line $\left(45^{0}\right.$ line $)$, implying that there is unequal distribution of income among the households in Nigeria. The payment concentration curve for social insurance contributions appears to lies above the equality line and the Lorenz curve at the initial level of consumption and latter crosses the Lorenz curve immediately after the first 20 percent of the population. This suggests regressivity in the first part of the consumption distribution and progressivity between the second 20 percent of the population to the last 20 percent of the population. Figure 1A further shows that the concentration curves for out of pocket payment lies above the Lorenz curve, suggesting regressivity. Figures $1 \mathrm{~B}$ and $1 \mathrm{C}$ are for urban and rural geometric representations. The gap between concentration curve for out of pocket and Lorenz curve is quite wide compared to the gap between concentration curve for social insurance contribution and Lorenz curve in figure 5.1C. This suggests that the value of KPI is higher for out of pocket payment than social insurance contribution when the signs are considered to be positive. For rural analysis in figure $5.1 \mathrm{~B}$, the gap between concentration curve for social insurance contribution and Lorenz curve is wider than that of the gap between concentration curve for out of pocket and Lorenz curve. This implies that the value of KPI for social insurance contributions is higher than out of pocket payment when the signs are considered to be positive.

The same interpretation goes for the figures 5.2a to 5.2c. The only notable difference between the first three figures and the last three figures is that the gap between the concentration curves for out of pocket payment and the Lorenz curves is wider for the first three figures compared to the last three figures. This implies that out of pocket payments for the first three figures are more regressive than the last three figures. 

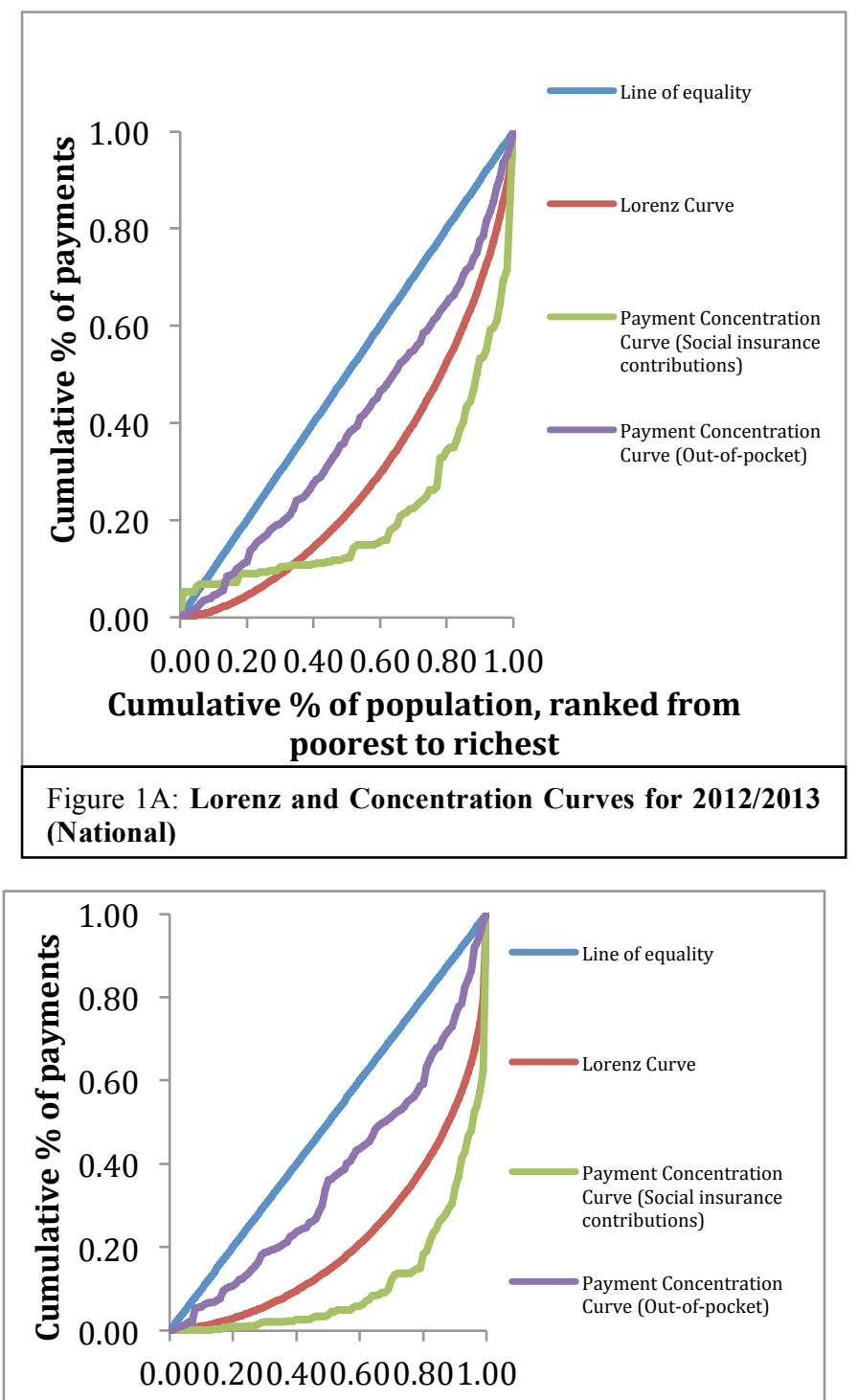

Cumulative \% of population, ranked from poorest to richest

Figure 1B: Lorenz and Concentration Curves for 2012/2013 (Rural)

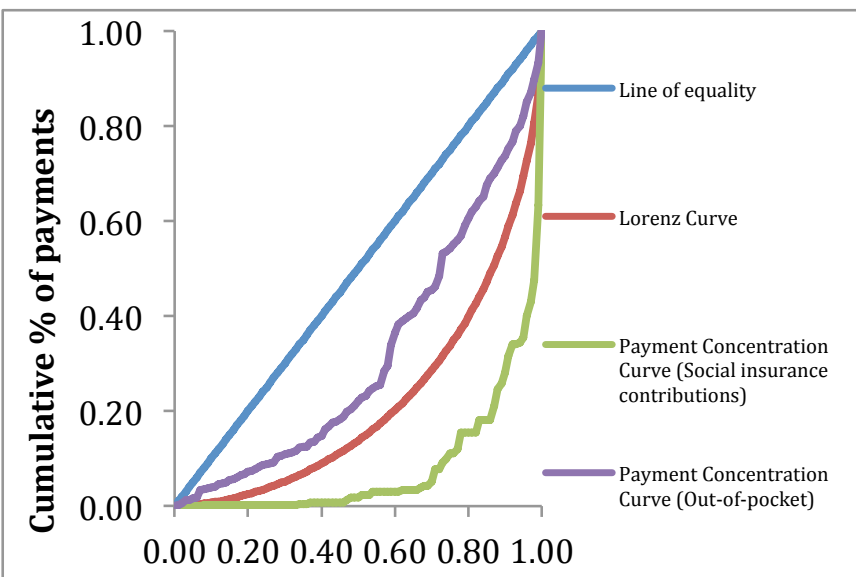

Cumulative \% of population, ranked from poorest to richest

Figure 1C: Lorenz and Concentration Curves for 2012/2013 (Urban)

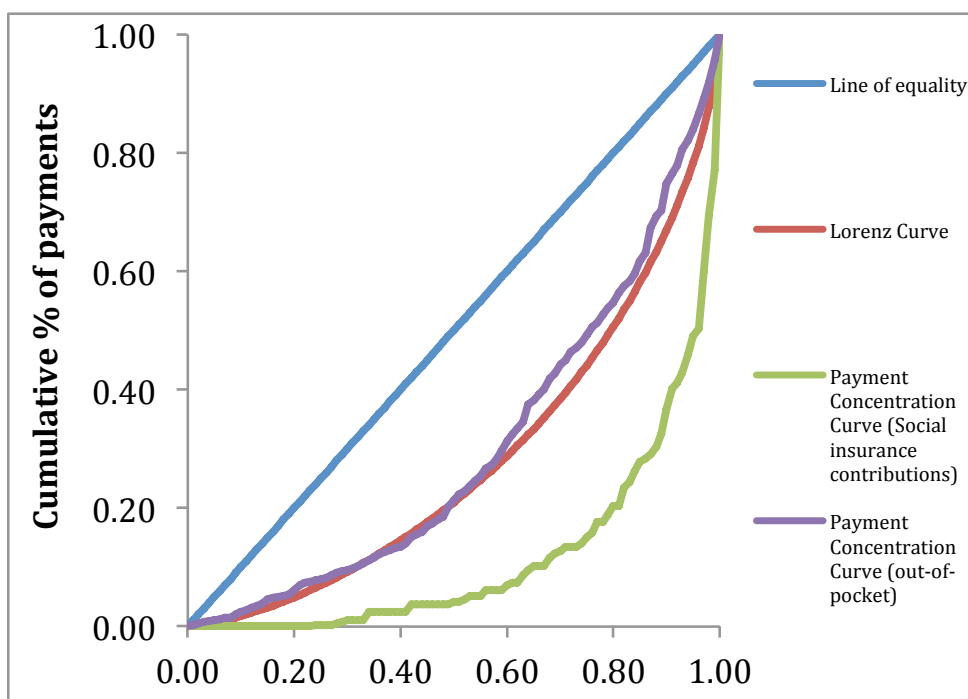

Cumulative \% of population, ranked from poorest to richest

Figure 2A: Lorenz and Concentration Curves for 2015/2016 (National)

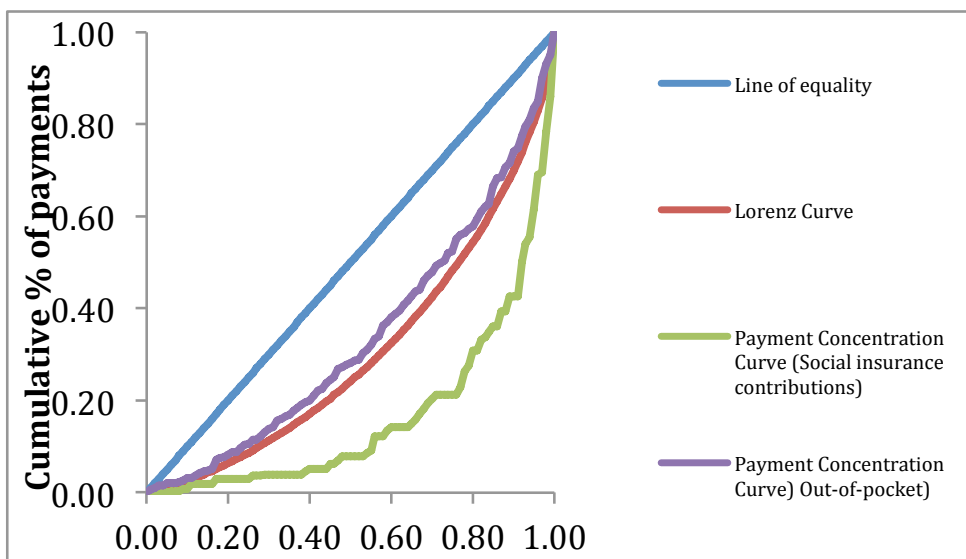

Cumulative \% of population, ranked from poorest to richest

Figure 2B: Lorenz and Concentration Curves for 2015/2016 (Rural)

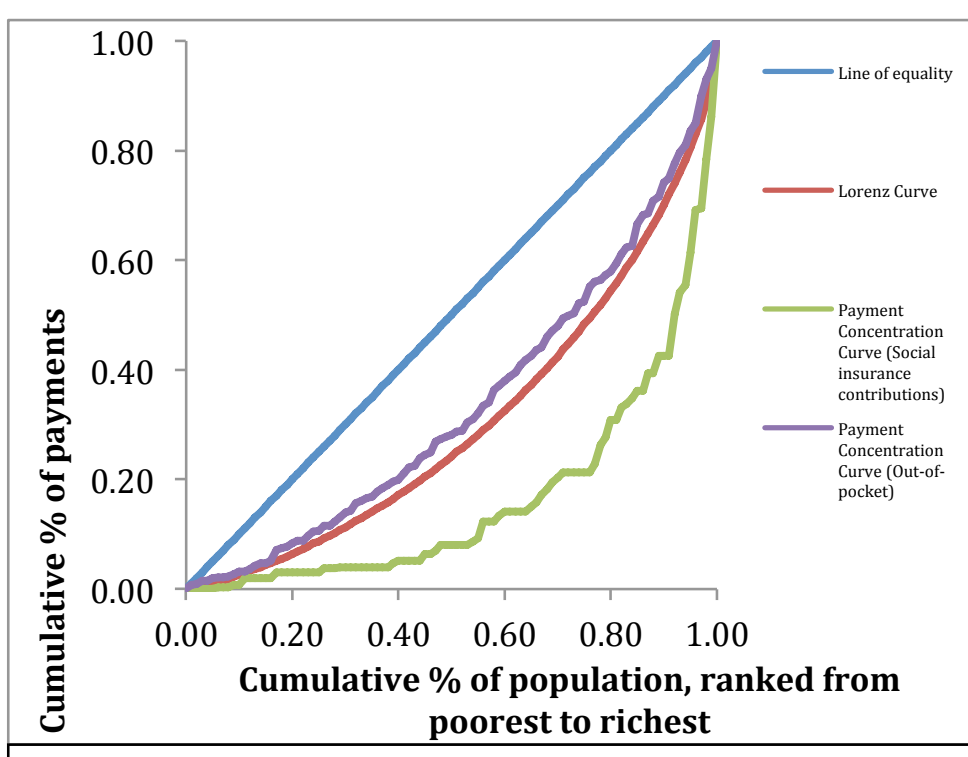

Figure 2C: Lorenz and Concentration Curves for 2015/2016 (Urban) 


\subsection{Conclusion and Recommendations}

Health is a critical component of well-being and an individual needs to nurture it with available care. However, some households/individuals may find it difficult to nurture due to the method of financing healthcare (specifically out of pocket), which might restraint access to the use of healthcare. Although, the volume and quality of healthcare needs vary from one individual to another but promoting access to the use of healthcare is germane to reduce/eliminate inequity in healthcare. Using a combination of Gini coefficient, Concentration Index, KPI, and MKD, this paper investigated the progressiveness of the healthcare financing in Nigeria. The progressivity results are geometrically corroborated by plotting the Lorenz curve and payments concentration curve for rural and urban sectors, as well as both sectors combined.

Generally, there are evidences of existence of income inequality on the aggregate, as well as across the sectors of urban and rural settings. The income inequality in Nigeria is further widened by the dominance of OOP and the associated regressive nature of the health financing mechanism. The results of the concentration index revealed that the non- poor devotes relatively greater proportion of their income on paying for healthcare services, compared to the poor. The OOP is generally pro-rich on the aggregate and across the urban and rural sectors. Out of pocket payment results indicate that payment for healthcare through out of pocket is concentrated among the poor households than income (regressive). The health insurance contribution as mode of paying for healthcare services revealed a progressive financial effect, as the proportion of income devoted to healthcare increases with increase in income. These assertions are supported by both the KPI and MDK results. However, the health insurance contribution is regressive among the rural dwellers, which is a reflection of the dominance of informal sector in the rural area, to which contributions are generally lump sum, due to difficulty $\mathrm{n}$ ascertaining the income package of individuals. Given that a more progressive healthcare financing approach tends to promote welfare and improve health status of the population, Nigeria will be better off promoting health insurance mechanism of financing healthcare. The current minimal coverage of less than $8 \%$ of the population requires appreciable push, to bring onboard workers at the state and local government levels, as well as the informal private sector. To protect the household from further impoverishment, efforts should be geared towards extending the NHIS beyond the federal government workers, while community health insurance should be widely extended to the rural areas.

\section{References}

1. Krutilova V. 2013. Cost sharing of patients for healthcare - forms, extent, impacts.

2. Mahapatro, M. 2013. Equity in utilization of healthcare services: Perspective of pregnant women in southern Odisha, India. National Institute of Health \& Family Welfare, New Delhi, India.

3. O’Donnell.O.,Van Doorslaer, E., Wagstaff, A. and Lindelow, M. 2008. Analyzing Health Equity Using Household Survey Data:A Guide to Techniques and Their Implementation. The International Bank for Reconstruction and Development / The World Bank.

4. Lagarde M. and Palmera N.2008. The impact of user fees on health service utilization in low- and middle-income countries: how strong is the evidence? Bulletin of the World Health Organization.

5. Abu-Zaineh Mohammad,Chokri Arfa,Bruno Ventelou,Habiba Ben Romdhane and Jean-Paul Moatti 2013. Fairness in healthcare finance and delivery: what about Tunisia?

6. Dalal, K., Aremu, O., Ussatayeva, G. and Biswas, A. 2017. Out of pocket Expenditure and Fairness in Utilization of Health care Facilities in 2005 and 2010. [version 1; referees: 2 approved] F1000Research 6:2066 (doi:10.12688/f1000research.12801.1).

7. Business Monitor International (BMI) Report 2015.

8. Cissé, B., Luchini, S. and Jean Paul Moatti 2009. Equity in Healthcare Finance and and Delivery :What about Africa?

9. Emshaw, D. 2010. Inequality and inequity in physician service utilization in Norway. 
10. Olaniyan, O., C. S. Oburota and F. N. Obafemi 2013. Equity in Healthcare Expenditure in Nigeria. International Journal of Finance \& Banking Studies, (2)3 2147-4486 available online at www.ssbfnet.com.

11. Teresa Bago d'Uvaa, Andrew M. Jones, Eddy van Doorslaer 2009. Measurement of horizontal inequity in health care utilisation using European panel data. Journal of Health Economics 28 (2009) 280-289

12. Lorant V., Boland B., Humblet P. and Deliege D. 2002. Equity in prevention and healthcare. $J$ Epidemiol Community Health, 56: 510-516.

13. Mohammad Abu-Zaineh, Awad Mataria, Ste'phane Luchini and Jean-Paul Moatti 2008. Equity in health care financing in Palestine: The value-added of the disaggregate approach. Social Science \& Medicine 66 (2008) 2308-2320.

14. O’Donnell O, Eddy van Doorslaer, Ravi P. Rannan-Eliya, Aparnaa Somanathan, Shiva Raj Adhikari, Baktygul Akkazieva, Deni Harbianto ,Charu C. Garg, Piya Hanvoravongchai, Alejandro N. Herrin, Mohammed N. Huq, Shamsia Ibragimova, Anup Karan, Soon-man Kwon, Gabriel M. Leung, Juifen Rachel, Yasushi Ohkusa, Badri Raj Pande, Rachel Racelis, Keith Tin, Kanjana Tisayaticom, Laksono Trisnantoro, Quan Wan, Bong-Min and Yuxin Zhao (2005). Who pays for healthcare in Asia?. EQUITAP Project: Working Paper \#1.

15. Ichoku, Fonta and Araar 2011. A Distributional Analysis of out-of-pocket Healthcare Financing in Nigeria Using a New Decomposable Gini Index. Journal of Applied Statistics 1(1): 65-77.

16. World Development Indicators 2017.

17. NHSMS report, 2015).

18. National Population Commission 2013. Nigeria Demographic and Health Survey (NDHS) 2103 (preliminary report). Abuja, Nigeria :NPC

19. USAID 2017. https://www.usaid.gov/nigeria/global-health

20. Kharas, H., Kristofer H. and Martin H. 2018. The Start of a New Poverty Narrative. World Bank's Brooking Institute 2018 Report.

21. Glied, S. A. 2008. Health Care Financing, Efficiency and Equity. National Bureau of Economic Research. Working paper 13881 available in http:// www.nber.org/papers/w13881

22. Gravelle, H. , S.Morris and M. Sutton 2006. Economic studies of equity in the consumption of healthcare. The Elgar Companion to Health Economics. 193-204.

23. Wagstaff Adam and Eddy Van Doorslaer 1998. Equity In Healthcare Finance And Delivery. Second Draft Prepared for Chapter 40, North Holland Handbook of Health Economics, (eds.) AJ Culyer and JP Newhouse.

24. Sen Amartha (1992) Inequality Re-examined. Oxford: Clarendon Press.

25. Neill Jon R. (2000). The benefit and sacrifice principles of taxation: A synthesis Social Choice. Journal of Social Choice Welfare 17:117-124.

26. Kakwani, C.N. 1977.Measurement of Tax Progressivity International comparison. The Economic Journal $* * * * *$.

27. Reynolds, M., and Smolensky, E. 1977. Public expenditures, taxes, and the distribution of income: The United States, 1950, 1961, 1970. New York: Academic Press.

28. Fukushige M., Ishikawa N. and Maekawa S. 2012. Modified Kakwani Measure for Health $\begin{array}{lllll}\text { Inequality. } \quad H e a l t h & \text { Economics } & \text { Review } & 2012 & \text { 2: }\end{array}$ http://www.healtheconomicsreview.com/content/2/1/10

29. Suits D.B. 1977. Measurement of tax progressivity. The American Economic Review 67 (4): 747-752

30. Atkinson, A. B. 1980. Horizontal Equity and the Distribution of Tax Burden.

31. Plotnick, R.D., (1981). A measure of horizontal equity. Review of Fconomics and Statistics 63,283288.

32. Plotnick, RD., 1982. The concept and measurement of horizontal equity. Journal of Public Economics 17, 373-391.

33. Berliant, M.C. and Strauss, R.P. 1983. Measuring the Distribution of Personal Taxes.

34. Berliant, M.C. and Strauss, R.P. 1985. The Horizontal and Vertical Equity Characteristics of the Federal Individual Income Tax 1966-1977.

35. Kaplow, L. 1989. Horizontal Equity: Measure in Search of a Principle. National Tax Journal 42:139154.

36. Slenick, D.T. 1989. The Measurement of Horizontal Inequality. Review of Economics and Statistics 71:481-490.

37. Onwujekwe, O., Chima Onoka, Benjamin Uzochukwu and Kara Hanson 2011. Constraints to universal coverage: inequities in health service use and expenditures for different health conditions and providers .International Journal for Equity in Health 10(50): 1-9. http://www.equityhealthj.com/content/10/1/50 
38. Ewelukwa, O., C. Onoka and O. Onwujekwe 2013. Viewing health expenditures, payment and coping mechanisms with an equity lens in Nigeria. BMC Health services research 13:87 http://www.biomedcentral.com/1472-6963/13/87

39. Mitei,G. S. Makawia, M. Ally, A. Kuwawenaruwa,F. Meheus and J. Borghi 2012. Who pays and who benefits from health care? An assessment of equity in health care financing and benefit distribution in Tanzania. Health Policy and Planning 2012;27:i23-i34.

40. Mills, A., J.E. Ataguba, J. Akazili, Jo Borghi, B. Garshong, S. Makawia, G. Mtei, B. Harris, J. Macha, F. Meheus and Di McIntyre 2012. Equity in financing and use of health care in Ghana, South Africa, and Tanzania: implications for paths to universal coverage.

41. Akazili,J., B. Garshong, M. Aikins, J. Gyapong and Di McIntyre 2012. Progressivity Of Health Care Financing And Incidence Of Service Benefits In Ghana. Health Policy and Planning 27:i13-i22 doi:10.1093/heapol/czs004

42. Chai Ping Yu, Whynes, K. and Sach, H. 2008. Equity in health care financing: The case of Malaysia. International journal for equity in health.

43. Crivelli, L. and Salari, P. (2014). The Inequity Of The Swiss Health Care System Financing From A Federal State Perspective. International Journal For Equity In Health. 